\title{
A timed test of swallowing capacity for neurological patients
}

\author{
K M Nathadwarawala, J Nicklin, C M Wiles
}

\begin{abstract}
A timed test of swallowing capacity has been designed for use in patients with neurogenic dysphagia. Swallowing speed $(\mathrm{ml} / \mathrm{s})$ has been demonstrated to have high intra- and inter- rater and test- retest reliability, and to be essentially independent of flavour or temperature. "Guideline" normal values were established in individuals without a swallowing disorder: swallowing speed was less in females than males and declined in both groups with age. The validity of a swallowing speed $<10$ $\mathrm{ml} / \mathrm{s}$ as an index of abnormal swallowing was tested by comparison with the complaint of abnormal swallowing in a group of 81 neurological patients. Swallowing speed had a sensitivity of $96 \%$ and specificity of 69\%: some apparent false positive responses were found in patients with disordered swallowing, mainly due to multiple sclerosis. Using a standard questionnaire and examination a similar pattern of symptoms and signs were statistically associated with both the clinical complaint of abnormal swallowing and swallowing speed. It is concluded that swallowing speed is a reliable and valid index for assessing disordered swallowing in neurological patients and may be of value in monitoring response to therapy.
\end{abstract}

(F Neurol Neurosurg and Psychiatry 1992;55:822-825)

Previous studies of patients with neuromuscular diseases monitored using quantitative strength measurements highlighted the need for some equivalent measure of swallowing capacity. ${ }^{1}$ We empirically introduced a simple timed test into the routine assessment of neuromuscular patients and subsequently have made preliminary reports on reliability ${ }^{2}$ and validity. $^{3}$

Department of

National Hospital for

Neurology and

Neurosurgery, Queen

Square, London, UK

$\mathrm{J}$ Nicklin

Department of

Medicine (Neurology),

University of Wales

College of Medicine

Heath Park, Cardiff

CF4 4XN, UK

K M Nathadwarawala

$\mathrm{C} M$ Wiles

Correspondence to: Professor Wiles.

Received 5 August 1991 and in final revised form 2 December 1991.

Accepted 18 December 1991

\section{Methods}

1) The technique for the swallowing test

The nature of the test is explained to the subject who should be seated upright, preferably on a chair at a table. The subject is given $150 \mathrm{ml}$ of cold tap water to drink from a standard glass: in patients predicted to have difficulty with this volume a lesser (measured) volume is given. The subject is asked to drink the water as quickly as possible but to take care and to stop if difficulty arises. The glass is held at the lips, until the "go" signal is given. The observer is seated at the side of the subject to obtain an adequate view of laryngeal movement during each swallow so that the number of swallows can be counted. The time and number of swallows taken from the "go" signal to the last swallow recognised by return of the larynx to the rest position (as seen exteriorly by the movement of the thyroid cartilage) are noted. Any coughing during or after the test and the quality of the voice after the test is noted. The residual volume is measured in those in whom the test is abandoned so that in all cases speed $(\mathrm{ml} / \mathrm{s})$, and average volume/ swallow (ml) are calculated. Such a test is clearly inappropriate in patients with major dysphagia who are obviously aspirating.

\section{2) Reliability studies}

Intra-rater reliability was assessed by one examiner timing twice the videotaped record of the swallows undertaken by six normal subjects or patients in random order and with the stopwatch face obscured. Inter-rater reliability was examined by 6 observers observing videos of swallowing tests on five normal subjects or patients. The possibility of a learning effect was tested in 24 normal subjects by repeating the test in each subject 4 times over a 48 hour period: at the same time the effect of flavouring the drink was assessed by randomising the order of the 4 drinks -2 of which were water and two a flavoured drink. The effect of temperature on swallowing speed was studied by presenting water at three different temperatures $\left(9^{\circ} \mathrm{C}, 19^{\circ} \mathrm{C}, 39^{\circ} \mathrm{C}\right)$ in random order to 6 normal subjects. Finally, swallowing speed was measured twice, at an interval of 1 to 37 days, in 38 neurological patients, of whom 24 had abnormal swallowing speeds (see below).

\section{3) Guideline normal ranges}

A swallowing test was undertaken in 101 "normal" subjects to establish a guideline range for swallowing speed. Individuals with clinically relevant medical or swallowing disorders were excluded.

\section{4) Validity studies}

The validity of the swallowing test was assessed by administering a questionnaire concerning symptoms related to impaired swallowing or aspiration, a standardised examination of the lower cranial nerves (V-XII), and the swallowing test (Table 3). Patients were initially categorised according to whether they perceived that they did or did not have a swallowing problem. As we had no reference test, the patients' perception ("yes" or "no") of a swallowing problem was taken as one variable 
in a series of cross-tabulations, using the answers to the questionnaire, scored physical examination and swallowing speeds. The sensitivity, specificity, and the positive predictive value of each feature were calculated. Secondly, similar calculations were performed using swallowing speeds of less or more than or equal to $10 \mathrm{ml} / \mathrm{s}$ (see below) as the index of abnormal or normal swallowing. The validity study included 81 inpatients with neurological diseases being investigated at a regional unit. There were 44 males, mean (SD) age 50.0 (13.9) years, and 37 females, mean (SD) age $50.4(17 \cdot 6)$ years.

\section{5) Ethical approval}

The studies were approved by the Ethics Committee at the National Hospital for Neurology and Neurosurgery and the Joint Ethics Committee of the University of Wales College of Medicine/South Glamorgan Health Authority. All' patients gave consent for the studies.

\section{Results}

\section{Reliability}

The differences between two measurements of swallowing speed by a single rater on each of six video-records of a $150 \mathrm{ml}$ swallowing test varied between 0.0 and 0.5 seconds, the difference on average being $2 \cdot 4 \%$ of the mean time for the two swallows (paired $t$ test, $\mathrm{p}=$ 0.32 ). An analysis of variance of the inter-rater results showed that $>99 \%$ of the variance was attributable to between patient differences $(F=10035, p<0.0001)$ and almost none due to order $(F=0.97, p=0.47)$ or interrater effects $(F=2 \cdot 88, p>0.05)$. There was no significant difference in the swallowing speed from the first to the fourth test over a 48 hour period in 24 normal subjects (paired $t$ test, $p=0 \cdot 194$ ), nor any significant effect of flavour or temperature. When 38 patients were retested between one and 37 days later, the mean (SD) difference in swallowing speed was $-0.17(1.98) \mathrm{ml} / \mathrm{s}$ and there was no systematic difference between the two occasions or with swallowing speed (range of speeds 1$37 \mathrm{ml} / \mathrm{s}$ ).

Guideline values for swallowing speed (Table 1) Swallowing speed declined with age in males $(r=0.70, p<0.001)$ and females $(r=0.58$, $\mathrm{p}<0.001$ ) (figure). Although several elderly subjects had rather low speeds, for subjects under 70 years age accounted for $32 \%$ and $16 \%$ of the variation ( $R^{2}$ values) in speed in males and females respectively. The variances of swallowing speed for males and females were
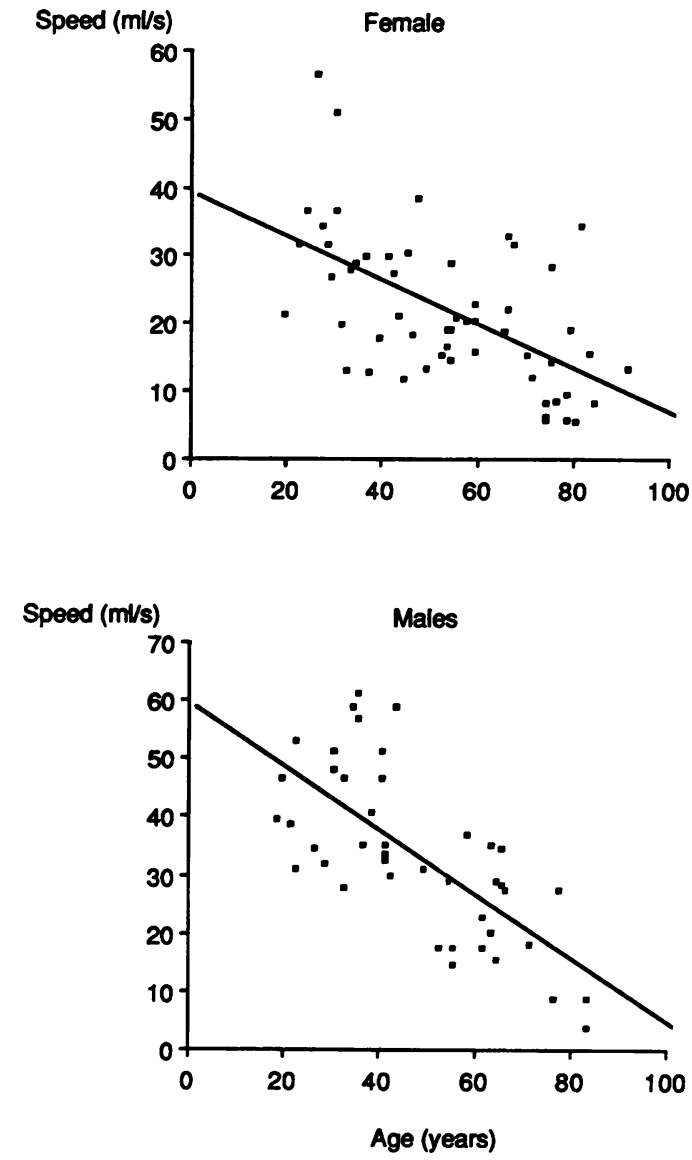

Figure Swallowing speed (y axis) and age ( $x$ axis) in 56 female and 45 male subjects without swallowing disorder. For females, $y=-0.324 x+37 \cdot 84, r=0.58$, $p<0.001$, corrected $R \hat{2}=0.33$. For males, $y=-0.548 x+57.553, r=0.70, p<0.001$, corrected $R \hat{2}=0.48$.

similar (variance ratio test, $p>0 \cdot 1$ ): the mean swallowing speed for all females $(n=56)$ and for females under 70 years old $(n=41)$ was less than for all males $(n=45)$ or males under 70 years old $(n=40)$ respectively (unpaired $t$ test, $t=4.476$ and $4 \cdot 117, p<0.001)$. None of 81 subjects (male or female) under the age of 70 years drank more slowly than $10.7 \mathrm{ml} / \mathrm{s}$.

\section{Validity}

A total of 81 neurological inpatients were classified according to whether they did (27) or did not (54) perceive a swallowing problem. Compared with both controls and those who denied a problem (table 1), the group which perceived a swallowing problem was slower (unpaired $t$ tests, $\mathrm{p}<0.001$ ). Most who complained of a swallowing problem drank at less than $10 \mathrm{ml} / \mathrm{s}$, that is, less than the minimum value for all normal subjects under 70 years

Table 1

\begin{tabular}{llllll}
\hline Group & Variable & $\begin{array}{l}\text { Normal } \\
\text { All subjects }\end{array}$ & $\begin{array}{l}\text { Subjects } \\
<70 \text { years }\end{array}$ & $\begin{array}{l}\text { Neurological inpatients } \\
\text { "no" problem }\end{array}$ & "yes" problem \\
\hline Female & number & 56 & 41 & 22 & 15 \\
& mean (SD) age in years & $52(19 \cdot 7)$ & $43(14 \cdot 2)$ & $49(17 \cdot 0)$ & $53(18 \cdot 9)$ \\
Male & mean (SD) speed in ml/s & $20 \cdot 90(10 \cdot 98)$ & $24 \cdot 2(9 \cdot 96)$ & $11 \cdot 8(7 \cdot 87)$ & $3 \cdot 0(2 \cdot 57)$ \\
& number & 45 & 40 & 32 & 12 \\
& mean (SD) age in years & $47(18 \cdot 1)$ & $43(15 \cdot 2)$ & $47(12 \cdot 9)$ & $58(13 \cdot 9)$ \\
& mean (SD) speed in ml/s & $32 \cdot 07(14 \cdot 01)$ & $34 \cdot 6(12 \cdot 6)$ & $20 \cdot 8(14 \cdot 4)$ & $4 \cdot 8(4 \cdot 5)$ \\
\hline
\end{tabular}


Table 2 Swallowing Problem (questionnaire response)

\begin{tabular}{llcl}
\hline Speed $(\mathrm{ml} / \mathrm{s})$ & No & Yes & Total \\
\hline$>10 \mathrm{ml} / \mathrm{s}$ & 37 & 1 & 38 \\
$<10 \mathrm{ml} / \mathrm{s}$ & 17 & 26 & 43 \\
Total & 54 & 27 & 81 \\
\hline
\end{tabular}

old. When swallowing was classified as fast $(=/>10 \mathrm{ml} / \mathrm{s})$ or slow $(<10 \mathrm{ml} / \mathrm{s})$, a strong relationship between swallowing speed and a perceived problem was evident (Chi squared $30.4, p<0.000$ ) (table 2). The sensitivity of a "slow" swallowing speed as an indicator of a stated swallowing problem was $96 \%$ and the specificity $69 \%$ : there was one false negative result in a patient with hiatus hernia. The positive predictive value of a swallowing speed $<10 \mathrm{ml} / \mathrm{s}$ was $60 \%$ and thus the false positive rate was $40 \%$. This latter group consisted of 17 patients therefore who drank slowly $(<10 \mathrm{ml} /$ s) but perceived no problem: 12 clearly had abnormal swallowing on other clinical criteria of whom seven had multiple sclerosis. Of the 18 patients with MS tested 11 had speeds $<10 \mathrm{ml} / \mathrm{s}$ of whom 7 denied a swallowing problem: on the basis of other elements in the questionnaire or on clinical examination, however, the latter had significant swallowing difficulties. Thus the clinical complaint of abnormal swallowing was less reliable than the timed test in multiple sclerosis patients.

Symptoms and signs in the questionnaire and examination were analysed by cross tabulation against "abnormal swallowing" judged either by the patients perception ("yes" or "no") or whether swallowing speed was $=/>$ or $<10 \mathrm{ml} / \mathrm{s}$. Symptoms and signs showed similar statistically significant associations with each criterion of abnormal swallowing (Chi squared test with continuity correction) (Table 3 ): for instance the symptom of having to be "careful" when eating or drinking was strongly associated with abnormal swallowing judged either by the patient's perception or a slow swallowing speed (Chi squared 43.72 and 31.70 , respectively $p<0.001$ ). By contrast dentures, cigarette smoking, previous ENT problems, a jaw jerk and tongue fasciculations showed no or only very weak associations. A number of symptoms and signs (indicated by stars in Table 3) including control of substances in the mouth, nasal regurgitation, chest infections in the previous year, palatal movement on vocalisation and pharyngeal sensation were abnormal on too few occasions to draw reliable statistical conclusions and thus were insensitive indices of abnormal swallowing by either cri-

Table 3 Symptoms and signs

\begin{tabular}{|c|c|c|c|c|c|c|}
\hline \multirow[b]{2}{*}{$\begin{array}{l}\text { Questions and pysical signs } \\
\text { Significant }(=<p 0.01) \text { associations } \\
\text { in descending order of significance }\end{array}$} & \multicolumn{6}{|c|}{ Reference test (Yes/no or Slow/fast) } \\
\hline & $\begin{array}{l}\text { Yes/no } \\
\text { Sensitivity } \\
(\%)\end{array}$ & $\begin{array}{l}\text { Slow/fast } \\
\text { Sensitivity } \\
(\%)\end{array}$ & $\begin{array}{l}\text { Yes/no } \\
\text { Specificity } \\
(\%)\end{array}$ & $\begin{array}{l}\text { Slow/fast } \\
\text { Specificity } \\
(\%)\end{array}$ & $\begin{array}{l}\text { Yes/no } \\
\text { Pos Pred Val } \\
\text { (\%) }\end{array}$ & $\begin{array}{l}\text { Slowlfast } \\
\text { Pos Pred Val } \\
\text { (\%) }\end{array}$ \\
\hline Careful when eating or drinking (yes/no) & 93 & 70 & 85 & 92 & 76 & 91 \\
\hline Food needing special preparation (yes/no) & 74 & 51 & 98 & 100 & 91 & 100 \\
\hline Cough during swallowing test (yes/no) & 67 & 44 & 98 & 100 & 95 & 100 \\
\hline Avoids some foods because difficult (yes/no) & 78 & 58 & 91 & 97 & 81 & 96 \\
\hline Coughing when eating or drinking $(0-1,2-4)$ & 70 & 49 & 91 & 92 & 79 & 88 \\
\hline Swallowing speed-(slow/fast) & 96 & & 69 & & 60 & \\
\hline Food or drink the wrong way $(0-1,2-4)$ & 63 & 42 & 93 & 92 & 81 & 86 \\
\hline Food getting stuck in the throat $(0-1,2-4)$ & 62 & 41 & 94 & 95 & 84 & 90 \\
\hline Clear throat (yes/no) & 48 & 30 & 87 & 97 & 93 & 93 \\
\hline Subjective feeling of voice change (yes/no) & 93 & 77 & 67 & 74 & 58 & 77 \\
\hline Speech $(0,1-3)$ & 93 & 79 & 67 & 76 & 58 & 79 \\
\hline Cough (abnormal/normal) & 67 & 47 & 87 & 87 & 72 & 80 \\
\hline Tongue movements (normal/slow) & 59 & 44 & 91 & 95 & 76 & 91 \\
\hline Waking up at night coughing $(0-1,2-4)$ & 48 & 30 & 96 & 95 & 87 & 87 \\
\hline Facial weakness (present/absent) & 56 & 37 & 93 & 92 & 79 & 84 \\
\hline \multirow{5}{*}{$\begin{array}{l}\text { Food left in the mouth after swallowing } \\
\quad(0-1,2-4) \\
\text { Rt. palatal reflex (present, slight to absent) } \\
\text { Lft. palatal reflex (present, slight to absent) } \\
\text { Lf. pharyngeal reflex (present, slight to } \\
\text { absent) }\end{array}$} & & & & & & \\
\hline & 46 & 31 & 96 & 97 & 87 & 93 \\
\hline & 67 & 49 & 78 & 76 & 60 & 70 \\
\hline & 67 & 51 & 77 & 78 & 60 & 73 \\
\hline & 63 & 47 & 83 & 84 & 65 & 77 \\
\hline \multirow{2}{*}{$\begin{array}{l}\text { Rt. pharyngeal reflex (present, slight to } \\
\text { absent) } \\
\text { Jaw weakness (present/absent) }\end{array}$} & & & & & & \\
\hline & $\begin{array}{l}56 \\
26\end{array}$ & $\begin{array}{l}44 \\
21\end{array}$ & $\begin{array}{l}80 \\
96\end{array}$ & $\begin{array}{r}82 \\
100\end{array}$ & $\begin{array}{l}58 \\
76\end{array}$ & $\begin{array}{r}73 \\
100\end{array}$ \\
\hline \multirow{6}{*}{$\begin{array}{l}\text { Non significant associations ( } p>0.05) \\
\text { Previous ENT problems (yes/no) } \\
\text { Tongue fasciculations (present/absent) } \\
\text { Jaw jerk (present/absent) } \\
\text { Dentures (yes/no) } \\
\text { Cigarettes smoking (yes/no) }\end{array}$} & & & & & & \\
\hline & 39 & 29 & 61 & 79 & 50 & 60 \\
\hline & 26 & 19 & 91 & 89 & 58 & 67 \\
\hline & 44 & 42 & 73 & 31 & 46 & 69 \\
\hline & 50 & 49 & 70 & 79 & 45 & 71 \\
\hline & 33 & 28 & 75 & 74 & 41 & 55 \\
\hline \\
\hline & & & & & & \\
\hline \multicolumn{4}{|l|}{$\begin{array}{l}(0-1,2-4) \\
\text { Liquids coming back through the nose }\end{array}$} & & & \\
\hline \\
\hline \multicolumn{6}{|l|}{$\begin{array}{l}\text { Chest infection in the last year }(0-1,2-3) \\
\text { Right pharyngeal sensation (present/absent) }\end{array}$} & \\
\hline \\
\hline & & & & & & \\
\hline Palate deviates (no, left, right) & & & & & & \\
\hline
\end{tabular}

$2 \times 2$ tables were constructed for symptoms and signs (according to the categories shown in brackets after each) against both reference tests. The clinical features in the right hand column are ranked from above down for association according to the significance values of chi-squared tests (with continuity correction). Thus for Careful when eating . . . Chi squared (yes/no) $=43 \cdot 72$, Chi squared $($ slow/fast $)=31.7(p<0.001)$ : for Jaw weakness Chi squared (yes/no) $=6.89$, Chi squared $($ slow/fast $)=6.95(p=$ 0.009). 
terion. The sensitivity, specificity and positive predictive value of each clinical feature for a "swallowing problem" defined by each of the two criteria are shown in table 3. Finally the questionnaire and examination together with ward observation including assessment by a speech therapist formed the basis of an overall judgement as to whether the patient did or did not have a swallowing problem (excluding the criterion of the swallowing test). A swallowing speed of $<10 \mathrm{ml} / \mathrm{s}$ was strongly associated with abnormal swallowing so defined (Chi square $56.02, \mathrm{p}<0.001$ ) with a sensitivity of $97 \%$, specificity $88 \%$, and a false positive rate of $12 \%$.

\section{Discussion}

A timed test of swallowing capacity is rapid, requires minimal equipment and could potentially be incorporated into the routine neurological examination. The data in normal subjects indicates that the test can be reliably carried out with minimal specific training. Repetition, flavour, and temperature had no systematic effect but data on this is inadequate for the elderly and children. There is evidence from the "guideline" normal data of slowing with age. The specific reason is unclear but natural caution, local factors including dentures, oral or pharyngeal dysfunction, ${ }^{4}$ cervical spondylosis (anterior osteophytes), chest disease and breathlessness, medication and occult disease of the CNS (for example, cerebrovascular disease, Parkinsonism) could all be factors which help to explain the high prevalences of swallowing problems in the elderly. ${ }^{67}$

It appeared important in testing neurological patients to ensure a comfortable posture, preferably seated at a table rather than in bed. Posture of the head and neck are potentially important influences on the capacity to swallow and carrying out such a test semirecumbent or in an uncomfortable position can be anticipated to reduce reliability. Impairment of conscious level or comprehension and lack of explanation also mitigate against reliable testing. The swallowing test itself will be potentially hazardous where the patient has overt aspiration or is strongly suspected of "silent aspiration" which may be difficult to confirm clinically ${ }^{8-10}$ and has pulmonary problems. The use of a swallowing speed (volume/ time) rather than the time of a fixed volume as the index in the test was chosen to allow the use of small volumes as dictated by clinical context. In some situations it will obviously be inappropriate to administer any fluid bolus by mouth and then the swallowing speed will be rated as zero.

Swallowing speed $(<10 \mathrm{ml} / \mathrm{s})$ was a sensitive indicator of a swallowing problem in this series of neurological inpatients. The validity of this measure was suggested by its high sensitivity and the similar pattern and degree of association with clinical consequences of dysphagia compared with the patient's perception of a swallowing problem. The specificity of $69 \%$ can be partly attributed to apparent false positive tests in patients (notably with multiple sclerosis) who did not perceive that they had a swallowing problem but had one on overall clinical evaluation.

A slow swallowing speed cannot of itself indicate the cause of abnormal swallowing, although observation of the patient drinking, the volume of each swallow, the presence of drooling, coughing during the test and the voice quality after the test together with the presence of any coughing may shed light on the underlying mechanisms. The test cannot, however, supplant radiological/manometric investigation or formal assessment by a speech therapist. Nevertheless, slow swallowing speed alone may usefully alert the clinician to neurogenic dysphagia as a potential problem and cause of respiratory complications.

In conclusion we find that a timed test of swallow capacity is a reliable and valid indicator of perceived swallowing problems in neurological patients. The test is simple and only briefly extends the neurological examination but may detect unexpected cases of abnormal swallowing and provides a convenient interval measure (speed in $\mathrm{ml} / \mathrm{s}$ ) with which to quantitate changes in swallowing. Routine use of such a test may help to shift the neurological assessment of the integrity of swallowing away from specific but insensitive signs of bulbar dysfunction to a more functional approach especially relevant when considering the respiratory consequences of neurological disease.

We are grateful to Christina Smith (Senior Speech Therapist at the National Hospital for Neurology and Neurosurgery) and Anna McGroary (Senior Speech Therapist at the University Hospital of Wales) for advice and help at various stages of this work. KMN was supported by a grant from the Welsh Scheme for the Development of Health and Social Research.

1 Wiles CM, Karni Y, Nicklin J. Laboratory testing of muscle function in the management of neuromuscular disease. $\mathcal{f}$ Neurol, Neurosurg Psychiatry 1990;53:384-7.

2 Nicklin J, Karni Y, Wiles CM. Measurement of swallowing time-a proposed method. Clin Rehab 1990;4:335-6.

3 Nathadwarawala KM, Nicklin J, Wiles CM. F Neurol, Neurosurg Psychiatry 1992.55:244-5.

4 Borgstrom PS, Ekberg O. Pharyngeal dysfunction in the elderly. $\mathcal{F}$ Medical Imaging 1988;2:74-81.

5 Bloem BR, Lagaay AM, van Beek W, Haan J, Roos RAC, Wintzen AR. Prevalence of subjective dysphagia in community residents aged over 87. BMF 1990;300 $721-2$

6 Sheth N, Diner WC. Swallowing problems in the elderly. Dysphagia 2 1988:209-15.

7 Logemann JA. Effects of aging on the swallowing mechanism. Otolaryngol Clin N America 1990;23:1045-56.

8 Horner J, Massey EW, Brazer SR. Aspiration in bilateral stroke patients. Neurol 1988;40:1686-8.

9 Splaingard ML, Hutchins B, Sulton L, Chauduri G. Aspiration in rehabilitation patients: videofluoroscopy vs bedside clinical assessment. Arch Phys Med Rehab 1988;69:637-9.

10 Linden P, Siebens A. Dysphagia: predicting laryngeal penetration. Arch Phys Med Rehab 1983;64:281-4. 